\title{
A profile of patients on ASA or NSAIDs hospitalized with upper gastrointestinal bleeding
}

\author{
Jessica Rieder, L DunCan SAunders, MB, BCH, PHD, Richard N Fedorak, MD
}

J RIEDER, LD SAUNDERS, RN FEDORAK. A profile of patients on ASA or NSAIDs hospitalized with upper gastrointestinal bleeding. Can J Gastroenterol $1993 ; 7(6): 459-465$.

BACKGROUND: The widespread use of nonsteroidal anti-inflammatory drugs (NSAIDs) and the relatively low risk of NSAID-induced gastric and duodenal ulceration in individual patients does not justify the use of prophylactic therapy in all NSAID users. It may be possible to identify a subgroup of patients on NSAIDs in which upper gastrointestinal bleeding might be prevented by prophylactic agents such as misoprostol. METHODS: The aims of this descriptive study were: to profile the characteristics of patients with upper gastrointestinal bleeding admitted to the University of Alberta Hospitals, Edmonton, Alberta between April 1988 and February 1991; to compare patients on NSAIDs who develop upper gastrointestinal bleeding with those taking neither NSAIDs nor ASA; and to identify the subgroup of patients prone to upper gastrointestinal bleeding that might benefit from prophylactic therapy. RESULTS: Of the 370 patients admitted with upper gastrointestinal bleeding, $58 \%$ had used NSAIDs or ASA up to $48 \mathrm{~h}$ prior to admission. There were twice as many males $(68 \%)$ as females $(32 \%)$ in the total study sample. In the total study sample, $55 \%$ were asymptomatic $48 \mathrm{~h}$ prior to admission. The subgroups with the highest proportions of NSAID use were women 70 years of age or older who were symptomatic, women 60 years of age or older with previous ulcer disease and who were asymptomatic, and women 70 years of age or older with previous ulcer disease who were asymptomatic. CONCLUSIONS: The results indicate that patients with gastrointestinal bleeds are more likely to be on NSAIDs. In the groups with the highest proportions of NSAID use, the effective prophylactic therapy might be cost-effective in preventing a high proportion of gastrointestinal bleeds from occurring.

Key Words: Acetylsalicylic acid, Bleeding, Nonsteroidal anti-inflammatory drugs

\section{Profil des patients sous AAS ou AINS hospitalisés pour hémorragie digestive haute}

RÉSUMÉ: L'usage répandu des AINS (anti-inflammatoires non stéroïdiens) et le risque relativement faible d'ulcération gastrique et duodénale liée aux AINS chez les individus ne justifient pas le recours à une prophylaxie chez tous les utilisateurs d'AINS. Il peut être possible d'identifier un sous-groupe de patients sous AINS

Division of Gastroenterology, Department of Medicine, and Department of Health Services, Administration 8 Community Medicine, University of Alberta, Edmonton, Alberta

Correspondence: Dr Richard N Fedorak, Division of Gastroenterology, Department of

Medicine, University of Alberta, 519 Robert Newton Research Building, Edmonton, Alberta

T6G 2C2. Telephone (403) 492-6941, Fax (403) 492-3744

Received for publication October 30, 1992. Accepted January 12, 1993
$\mathrm{I}^{\mathrm{r}}$ N THE PAST DECADE, NONSTEROIDAL anti-inflammatory drug (NSAID) use has increased with the ageing of the North American population (1). In fact, NSAIDs are the most commonly prescribed agents for the treatment of musculoskeletal chronic pain and arthritic syndromes (2). Several studies have demonstrated that the risk of gastroduodenal ulceration and its associated life-threatening complications are increased two- to fourfold in NSAID users (2-4). The identification of risk factors predisposing NSAID users to damaging complications is presently the study of many investigators.

Ulcers related to NSAID use differ from classic peptic ulcers in that they occur mainly in the stomach, are not necessarily acid dependent, and are often asymptomatic $(5,6)$. By inhibiting gastric mucosal cyclo-oxygenase and reducing endogenous mucosal prostaglandin synthesis, NSAIDs appear to interfere with mucosal protection, rendering the mucosal cells of the stomach wall susceptible to the damaging effects of gastric secretions. The prophylactic administration of misoprostol (Cytotec, GD Searle), a synthetic analogue of the naturally occurring prostaglandin $\mathrm{E}$, has recently been shown to prevent NSAID-induced gastric ulceration (5).

The widespread use of NSAIDs and the relatively low risk of NSAID-induced gastric and duodenal ulceration does not appear to justify the use of 
chez qui les hémorragies digestives hautes peuvent être prévenues grâce à des agents prophylactiques comme le misoprostol. MéTHODES : Les buts de cette étude descriptive étaient d'énumérer les caractéristiques des patients atteints d'hémorragie digestive haute admis dans les hôpitaux de l'Université de l'Alberta, Edmonton, entre avril 1988 et février 1991; de comparer les patients sous AINS qui présentent des hémorragies digestives hautes à ceux qui ne prennent ni AINS, ni AAS; et d'identifier les sous-groupes de patients sujets aux hémorragies digestives hautes qui bénéficieraient d'une prophylaxie. RÉSUltATS : Des 370 patients admis pour une hémorragie digestive haute, $58 \%$ avaient utilisé des AINS ou de l'AAS jusqu'à 48 heures avant leur admission. Il y avait deux fois plus de sujets de sexe masculin $(68 \%)$ que de sexe féminin (32\%) dans l'échantillon complet de l'étude. Dans cet échantillon, $55 \%$ étaient asymptomatiques 48 heures avant l'admission. Les sous-groupes dans lesquels l'emploi des AINS était le plus répandu étaient constitués de femmes de 70 ans ou plus symptomatiques, de femmes de 60 ans ou plus ayant des antécédents d'ulcères asymptomatiques, et de femmes de 70 ans ou plus ayant des antécédents d'ulcères asymptomatiques. CONCLUSIONS : Les résultats indiquent que les patients qui souffrent d'hémorragie digestive sont plus susceptibles d'être sous AINS. Dans le groupe où l'emploi d'AINS est le plus répandu, une prophylaxie efficace peut être rentable pour prévenir une bonne part des hémorragies digestives.

prophylactic therapy for all NSAID users. It may be possible, however, to identify a subgroup of patients on NSAIDs in which upper gastrointestinal bleeding might be prevented by a prophylactic agent such as misoprostol.

The aims of this descriptive study were: to profile the characteristics of patients with upper gastrointestinal bleeding admitted to the University of Alberta Hospitals in Edmonton, Alberta between April 1988 and February 1991; to compare those patients on NSAIDs who developed upper gastrointestinal bleeding with those taking neither NSAIDs nor acetylsalicylic acid (ASA) and with those on ASA; and to identify age-sex defined groups with upper gastrointestinal bleeding with the highest proportion of NSAID use.

\section{PATIENTS AND METHODS}

All those patients admitted to the University of Alberta Hospitals between April 1988 and February 1991 for gastric, duodenal, gastroduodenal, or other (unspecified) ulceration with acute complications of bleeding (verified by hematemesis, melena, or bleeding documented by upper panendoscopy), or bleeding and perforation (verified by upper panendoscopy) were considered eligible for the study (Figure 1). The evaluation included all records which indicated a primary diagnosis of gastric ulcer (ICD 9-CM codes 531.0 to 531.8 , except 531.3 and
531.7), duodenal ulcer ( 532.0 to 532.8 , except 532.3 and 532.7), peptic ulcer (site unspecified - 533.0 to 533.8 , except 533.3 and 533.7), and gastrojejunal ulcer ( 534.0 to 534.8 , except 534.3 and 534.7 - where .0 signifies acute with hemorrhage, .1 signifies acute with perforation, .2 signifies acute with hemorrhage and perforation, 3 signifies acute without mention of hemorrhage or perforation, .4 signifies chronic or unspecified with hemorrhage, .5 signifies chronic or unspecified with perforation, .6 signifies chronic or unspecified with hemorrhage and perforation, .7 signifies chronic without mention of hemorrhage or perforation, and .8 signifies unspecified as acute or chronic without mention of hemorrhage or perforation).

A record review confirmed that, of the 1017 patients whose charts were identified with the ICD 9-CM codes mentioned above, only 417 actually presented to the hospital with a chart history documenting upper gastrointestinal bleeding on that admission in the interval between April 1988 to February 1991 (Figure 1). The remainder of the patients' charts (600) with these ICD 9-CM codes, represented documentation of previous gastrointestinal bleeding events. To define the study sample further, only patients with documented NSAID and/or ASA use or nonuse were studied. As a result of this selection process, only 370 of the 417 eligible patient charts could be evaluated. Table 1 lists the information obtained from each patient chart.

Patients were organized into four groups: I, those taking NSAIDs; II, those taking ASA; III, those taking both NSAIDs and ASA; and IV, those using neither drug. Since the profile of a patient with an upper gastrointestinal bleed on NSAIDs might differ from that of one on ASA, patients on ASA were excluded from the NSAID group. Similarly, the profiles of patients on NSAIDs or ASA were distinguished from the profiles of patients on both NSAIDs and ASA.

The data were analyzed using the Statistical Package for the Social Sciences (SPSS/PC+) to calculate the varying proportions of patients in each of the categories for the four different groups. Chi-square tests with Yates' correction were used to test for significant differences between the proportions obtained for patients on NSAIDs, patients on ASA, and those on neither drug. The proportion of NSAID use by subgroups, as defined by age and sex, was calculated using confidence intervals.

\section{CHARACTERISTICS OF STUDY SAMPLE}

Of 370 patients evaluated, $58 \%$ had used NSAIDs or ASA up to $48 \mathrm{~h}$ prior to admission. The percentage of patients on NSAIDs alone $(22 \% ; 81$ of 370$)$ was similar to that of patients taking ASA alone $(27 \% ; 100$ of 370$)$, while only $9 \%$ ( 35 of 370 ) were taking both, and $42 \%$ (154 of 370 ) were taking neither drug. Demographics: There were more than twice as many males (68\%) as females $(32 \%)$ in the total study sample $(\mathrm{P}<0.05)$ (Figure 2). Furthermore, there were more males than females in each of the groups studied; however, in groups taking NSAIDs, the relative number of females increased. In the total study sample, females $(67.2 \pm 1.3$ years) were significantly older than males $(60.5 \pm 1.1$ years) $(\mathrm{P}<0.05)$ (Figure 3$)$.

Clinical presentation: Data for the presence of clinical symptoms $48 \mathrm{~h}$ prior to presentation were available in $92 \%$ (339 of 370) of patients. In the total study sample, $55 \%$ (187 of 339 ) were 
asymptomatic (without pain, nausea, or vomiting) in the $48 \mathrm{~h}$ prior to admission, and $45 \%$ (152 of 339 ) were symptomatic (Figure 4).

Diagnosis, therapy and outcome: Data for endoscopy, surgery and death as an outcome were available in 100\% (370 of 370) of patient charts evaluated. Following admission, 92\% (339 of 370) of the total study sample received diagnostic upper panendoscopy, 22\% (80 of 370) received therapeutic endoscopy (injection or bipolar electrocoaptation hemostasis) (Table 2), 14\% (51 of 370) underwent surgery (Figure 5), and 6\% (24 of 370) died (Figure 6). Figure 7 demonstrates that almost 60\% (219 of 370) of these patients presented with a gastric ulcer while $49 \%$ (181 of 370 ) presented with a duodenal ulcer. Of the 219 gastric ulcers demonstrated on endoscopy, $28 \%$ were located in the antrum, $20 \%$ in the body, $11 \%$ in the pylorus, $4 \%$ in the fundus, and $4 \%$ in the cardia.

Health, family and social history: Data for past ulcer disease, family and social history were available in 94\% (348 of 370$), 55 \%$ (203 of 370) and $89 \%$ (332 of 370 ) of patients, respectively. Table 3 indicates that $46 \%$ of the patients in the total study sample had had a previous ulcer, and 20\% had a family history of ulcer disease. Patients were assumed to be abusing alcohol if 'alcohol abuse' was documented in the chart history. Alcohol abuse was recorded for $20 \%$ of the patients, and $34 \%$ smoked at least one pack per day.

Table 4 documents the frequencies of NSAID use. The four most commonly used NSAIDs accounted for nearly $80 \%$ of those used. In descending order of frequency, these were: indomethacin, diclofenac, piroxicam, and naproxen.

\section{COMPARISON OF NSAID} USERS TO PATIENTS USING NEITHER NSAIDS NOR ASA

Demographics: In comparing patients with gastrointestinal bleeds on NSAIDs with those on neither NSAIDs nor ASA, Figure 2 indicates that, although the number of males was higher in both groups, the proportion of females in the NSAID group (46\%) was significantly higher $(\mathrm{P}<0.05)$ than that found in the
TABLE 1

Information obtained from patients admitted to the University of Alberta Hospitals with an upper gastrointestinal bleed in the interval between April 1988 and February 1991

\begin{tabular}{ll}
\hline Information categories & Variables \\
\hline Demographics & Patient sex \\
& Patient age \\
Drug use & NSAID use \\
& Most frequently used NSAIDs \\
& ASA use \\
Clinical presentation & Presence of symptoms 48 h prior to \\
& presentation \\
Diagnosis, therapy, and outcome & Ulcer location \\
& Use of diagnostic endoscopy \\
& Use of therapeutic endoscopy \\
& Use of bipolar electrocoaptation (BICAP) \\
& Use of injection hemostasis \\
& Use of surgical therapy \\
& Death as an outcome \\
Past medical history & Previous ulcer disease \\
Family and social history & Family history of ulcer disease \\
& Alcohol use \\
& Smoking habits \\
\hline
\end{tabular}

ASA Acetylsalicylic acid; NSAIDs Nonsteroidal anti-inflammatory drugs

\section{Selection of Patients Eligible for the Study}

patients hospitalized between April 1988

and February 1991 with ICD-9-CM codes

indicating a bleeding or bleeding and

perforated ulcer
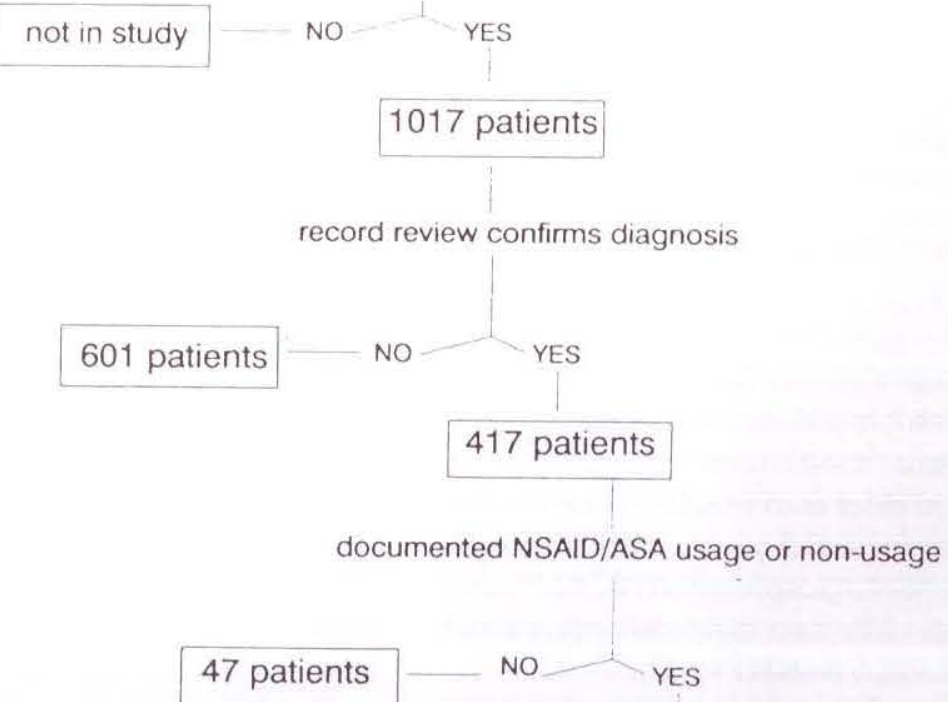

370 patients 


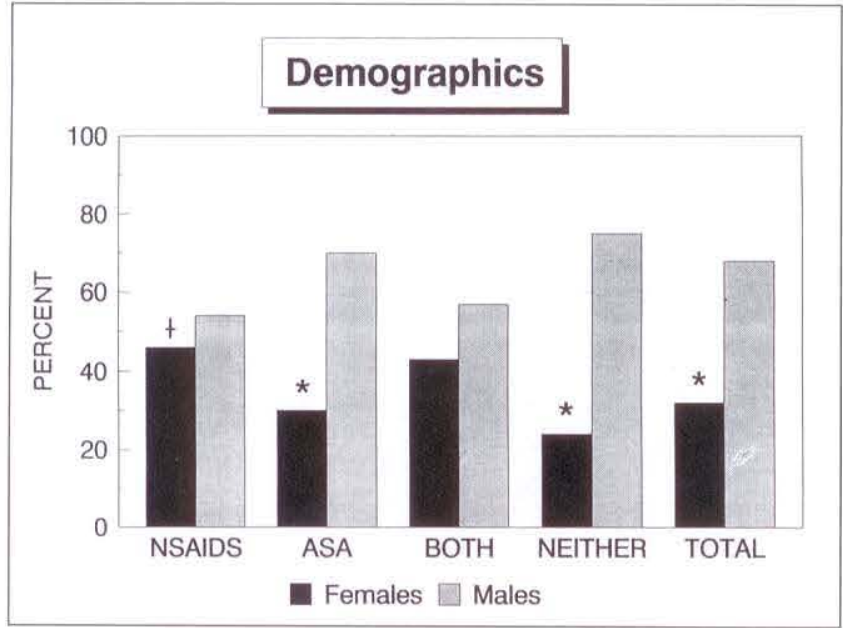

Figure 2) Percentage of females $(F)$ and males $(M)$ in each group. Values for N/total are: NSAIDs 37/81 F, 44/81 M; ASA 30/100 F, 70/100M; Both 15/35 F, 20/35 M; Neither 38/154 F, 116/154 M; Total $120 / 370 \mathrm{~F}, 250 / 370 \mathrm{M}$. $* P<0.05$, females relative to males within the group; ${ }^{\dagger} P<0.05$, female NSAID relative to females in the neither and ASA groups

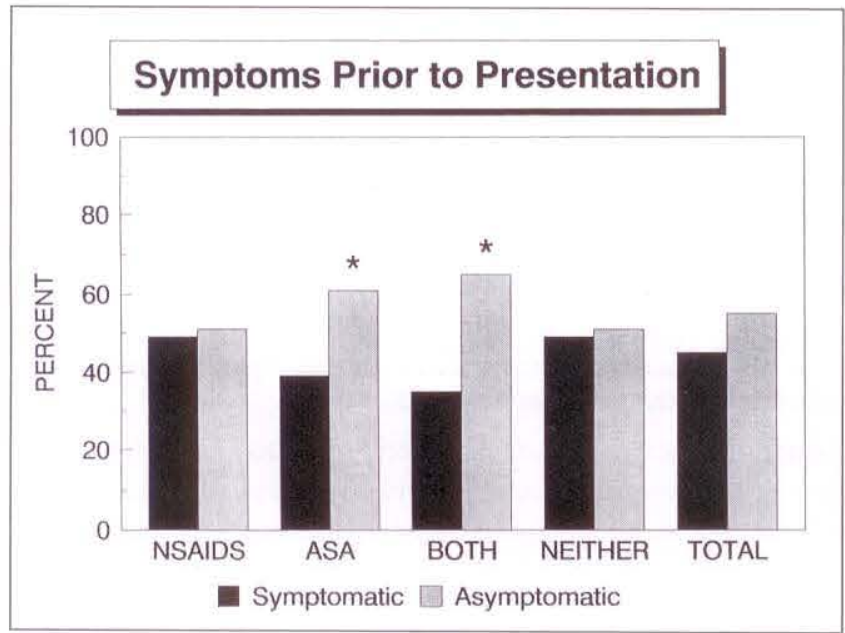

Figure 4) Presence of clinical symptoms prior to presentation. Values for N/total (symptomatic, asymptomatic) are: NSAIDs 68/139. 71/139; ASA 37/95, 58/95; Both 11/31, 20/31; Neither 68/139, 71/139; Total 152/339, 187/339. ${ }^{*} \mathrm{P}<0.05$, asymptomatic relative to symptomatic within the group

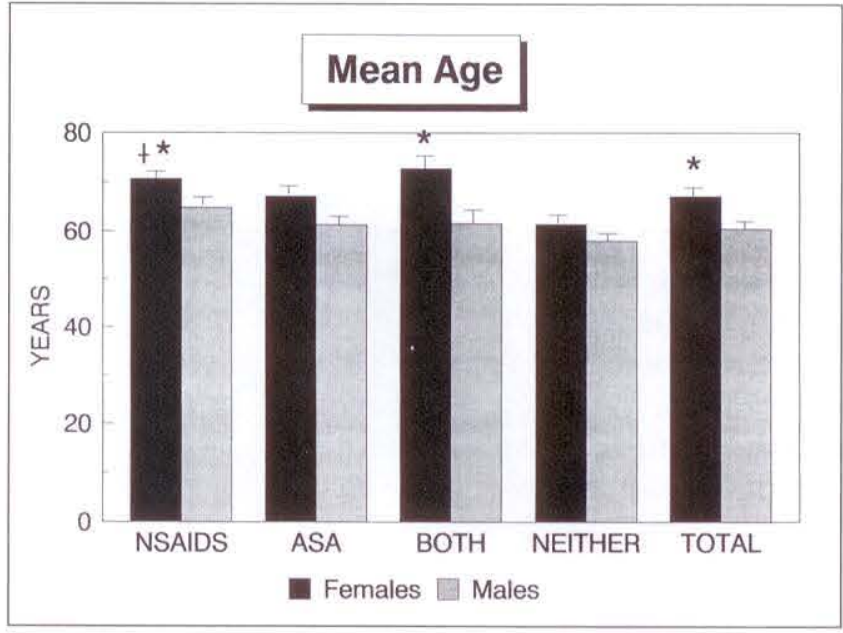

Figure 3) Age at presentation for females and males in each group expressed in mean years $\pm S D$. ${ }^{*} P<0.05$, females relative to males within the group; ${ }^{\dagger} P<0.05$, female NSAID relative to females in the neither group

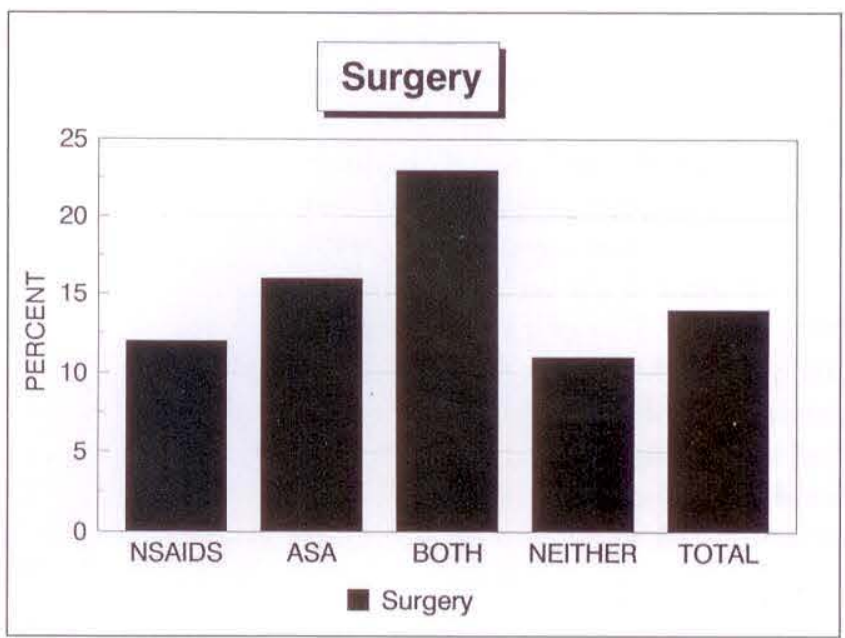

Figure 5) Percentage of patients requiring surgery. Values for N/total for each group are: NSAIDs 10/81; ASA 15/100; Both 8/35; Neither 18/154; Total 51/370 group with neither NSAIDs nor ASA $(24 \%)$. In addition, as shown in Figure 3, female NSAID users $(70.7 \pm 2.1$ years $)$ were older than females taking neither drug $(61.5 \pm 2.5$ years $)(\mathrm{P}<0.05)$. Within the NSAID group females $(70.7 \pm 2.1$ years) were older than their counterpart males (62.9 \pm 2.5 years) $(\mathrm{P}<0.05)$.

Clinical presentation: Figure 4 shows that the proportion of NSAID users who were asymptomatic prior to presentation $(51 \%)$ was similar to the proportion of NSAID users who were symptomatic $(49 \%)$, and was not sig- nificantly different from the proportion of patients using neither NSAIDs nor ASA (51\%) who were asymptomatic prior to presentation.

Diagnosis, therapy, and outcome: There was no significant difference between the proportion of patients in the NSAID group ( $86 \%$ ) and the group taking neither drug (92\%) who underwent diagnostic upper panendoscopy, whereas patients on NSAIDs $(11 \%)$ were less likely $(\mathrm{P}<0.05)$ than those taking neither drug $(23 \%)$ to have had therapeutic endoscopy (Table 2). Although the proportion of patients on NSAIDs who underwent surgery for ulcer complications $(12 \%)$ was not significantly different from that of those taking neither drug (11\%) (Figure 5), a lower proportion of NSAID users died $(\mathrm{P}<0.05) \quad$ (Figure 6). Patients on NSAIDs were more likely $(P<0.05)$ to develop gastric ulcers (67\%)than were those patients taking neither NSAIDs nor ASA (51\%). Furthermore, the NSAID users themselves were more likely to have a gastric than duodenal 


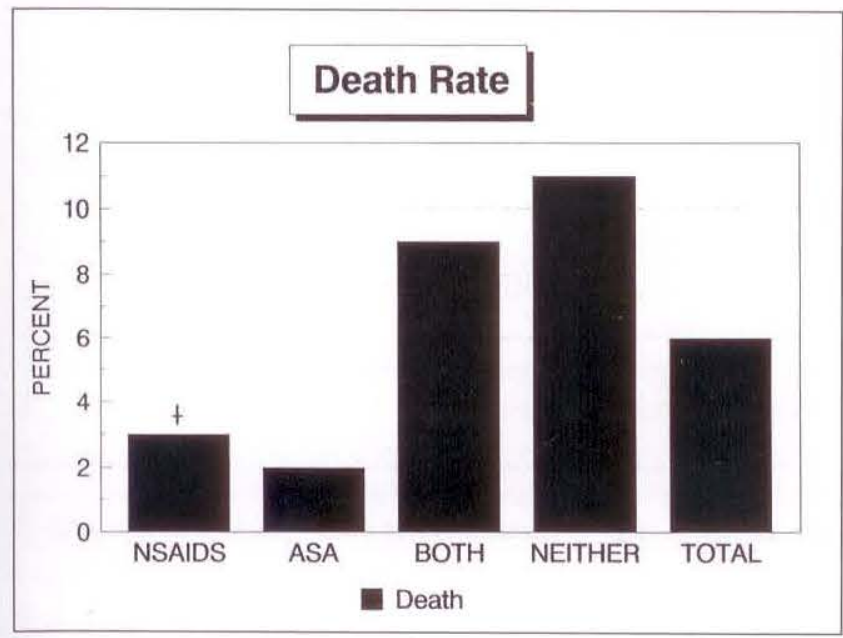

Figure 6) Death rates for each group. Values for $N /$ total are: NSAIDs 2/81; ASA 2/100; Both 3/35; Neither 18/154; Total 24/370. $* \mathrm{P}<0.05$, NSAIDs relative to the neither group

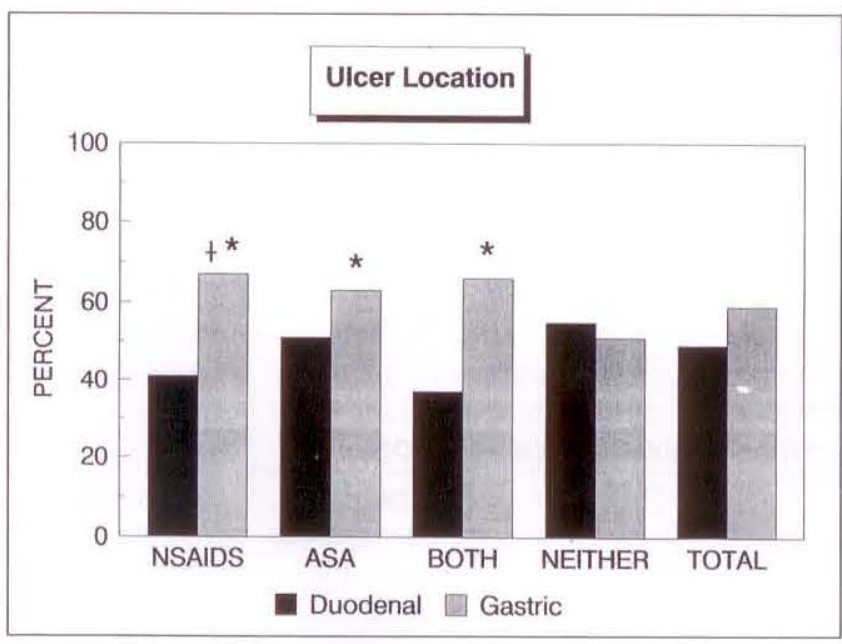

Figure 7) Duodenal or gastric ulcer location in each group. Values for N/total (duodenal, gastric) are: NSAIDs 33/81, 54/81; ASA 51/100, 63/100; Both 13/35, 23/35; Neither 84/154, 79/154; Total 181/370, $219 / 370 . * P<0.05$, gastric relative to duodenal ulcers within the group; ${ }^{\dagger} P<0.05$, relative to gastric ulcers in the neither group ulcer $(\mathrm{P}<0.05)$ (Figure 7). In contrast, the group taking neither NSAIDs nor ASA developed duodenal ulcers more frequently, although this did not reach statistical significance.

Health, family, and social history: Table 3 indicates that the proportion of patients on NSAIDs who had had a previous ulcer, had a family history of ulcer disease, and had smoked at least one pack per day, was not significantly different from the number of those patients on neither drug with a similar history. $\mathrm{Pa}$ tients on NSAIDs were less likely to abuse alcohol $(\mathrm{P}<0.05)$ than were patients on neither drug.

\section{COMPARISON OF NSAID USERS TO ASA USERS}

Demographics: Figure 2 shows that the proportion of females in the NSAID group (46\%) was significantly higher $(\mathrm{P}<0.05)$ than the proportion of $\mathrm{fe}-$ males in the ASA group (30\%). The proportions for males were reversed, with more males taking ASA (70\%) than NSAIDs $(54 \%) \quad(\mathrm{P}<0.05)$. Although both male and female NSAID users were older than ASA users, the values were not significantly different (Figure 3).

Clinical presentation: As shown in Figure 4, patients on ASA were more likely to be asymptomatic than symptomatic prior to presentation $(\mathrm{P}<0.05)$.
The proportion of NSAID users who were asymptomatic $48 \mathrm{~h}$ prior to presentation $(51 \%)$ was not significantly different from that of asymptomatic ASA users (61\%) (Figure 4).

Diagnosis, therapy, and outcome: While the proportions of patients receiving diagnostic upper panendoscopy were similar in the NSAID (86\%) and ASA (94\%) group, a significantly lower $(\mathrm{P}<0.05)$ proportion of NSAID users $(11 \%)$ received therapeutic endoscopy than did ASA users (27\%) (Table 2). Both NSAID users and ASA users were more likely to present with gastric ulcers, particularly antral and body, than with duodenal ulcers $(\mathrm{P}<0.05)$ (Figure 7). There was no significant difference between the proportions of NSAID users and ASA users who underwent surgery and died (Figures 5 and 6, respectively). Health, family, and social history: In comparing NSAID and ASA users, the proportions of patients with a history of a previous ulcer or a family history of ulcer disease, alcohol abuse, or smoking more than one pack per day, were not significantly different (Table 3).

\section{PATIENTS WITH GI BLEEDS WITH A HIGH RATE OF NSAID USE}

Table 5 shows the percentage of NSAID users in different age and sex groups. Patients at least 45 years old had a greater percentage of NSAID users than younger patients $\left(\chi^{2}=10.0\right.$, $\mathrm{P}<0.002$ ). Females at least 75 years old had the highest percentage of NSAID use.

\section{UNAVAILABLE INFORMATION}

Due to insufficient historical information in patient charts (available in less than $70 \%$ of the total study population), the following information could not be adequately evaluated from the 370 patient charts used: NSAID treatment duration, NSAID dosage, ASA treatment duration, ASA dosage, presence of a concomitant chronic illness, year of previous ulcer, previous ulcer complications, location of previous ulcer, and coffee consumption.

\section{DISCUSSION}

Several studies have attempted to identify factors which contribute to NSAID-induced ulcer occurrence and complications. To complete the first objective of this study, the proportions of patients taking NSAIDs, ASA, both drugs, or neither drug were calculated for patients admitted to the University of Alberta Hospitals with an upper gastrointestinal bleed over a 35 month interval. The proportions obtained were used both to create a profile of the patient admitted with an upper gastrointestinal bleed and to compare those on NSAIDs with both those taking 
TABLE 2

Diagnosis

\begin{tabular}{lccccc}
\hline & $\begin{array}{c}\text { NSAIDs } \\
\text { number/total }(\%)\end{array}$ & $\begin{array}{c}\text { ASA } \\
\text { number/total }(\%)\end{array}$ & $\begin{array}{c}\text { Both } \\
\text { number/total (\%) }\end{array}$ & $\begin{array}{c}\text { Neither } \\
\text { number/total }(\%)\end{array}$ & $\begin{array}{c}\text { Total } \\
\text { number/total }(\%)\end{array}$ \\
\hline Diagnostic endoscopy & $70 / 81(86)$ & $94 / 100(94)$ & $33 / 35(94)$ & $142 / 154(92)$ & $339 / 370(92)$ \\
Therapeutic endoscopy & $9 / 81(11)$ & $27 / 100(27)$ & $9 / 35(26)$ & $35 / 154(23)$ & $80 / 370(22)$ \\
\hline
\end{tabular}

${ }^{*} P<0.05$ NSAID relative to group on neither drug: ${ }^{\dagger} P<0.05$ NSAID relative to ASA group

TABLE 3

Health, family, and social history

\begin{tabular}{lccccc}
\hline & $\begin{array}{c}\text { NSAIDs } \\
\text { number/total (\%) }\end{array}$ & $\begin{array}{c}\text { ASA } \\
\text { number/total (\%) }\end{array}$ & $\begin{array}{c}\text { Both } \\
\text { number/total (\%) }\end{array}$ & $\begin{array}{c}\text { Neither } \\
\text { number/total (\%) }\end{array}$ & $\begin{array}{c}\text { Total } \\
\text { number/total (\%) }\end{array}$ \\
\hline Previous ulcer & $31 / 74(40)$ & $45 / 98(46)$ & $12 / 32(38)$ & $17 / 141(50)$ & $159 / 348(46)$ \\
Family history of ulcer & $7 / 41(17)$ & $9 / 58(16)$ & $5 / 20(25)$ & $20 / 85(24)$ & $41 / 203(20)$ \\
Alcohol 'abuse' & $6 / 64(9)^{*}$ & $13 / 83(16)$ & $6 / 27(22)$ & $36 / 133(27)$ & $61 / 307(20)$ \\
Smoke (>1 pack/day) & $18 / 69(26)$ & $33 / 95(35)$ & $8 / 29(28)$ & $53 / 139(38)$ & $112 / 332(34)$ \\
\hline
\end{tabular}

* $P<0.05$ relative to group on neither drug

TABLE 4

Frequencies of NSAIDs use

\begin{tabular}{lrr}
\hline NSAID & \multicolumn{2}{c}{ Number (\%) } \\
\hline Indomethacin & 24 & $(30)$ \\
Diclofenac & 22 & $(27)$ \\
Piroxicam & 9 & $(11)$ \\
Naproxen & 8 & $(10)$ \\
Ketoprofen & 5 & $(6)$ \\
Flurbiprofen & 2 & $(2)$ \\
Ibuprofen & 2 & $(2)$ \\
Tiaprofenic acid & 2 & $(2)$ \\
Tolmetin & 2 & $(2)$ \\
Diflunisal & 1 & $(1)$ \\
Sulindac & 1 & $(1)$ \\
Not specified & 3 & $(2)$ \\
Total & 81 & $(100)$ \\
\hline
\end{tabular}

neither NSAIDs nor ASA and those taking ASA.

Although females using NSAIDs did not present with a bleeding ulcer any more than did males using NSAIDs, the proportion of NSAID-using females admitted to the University of Alberta Hospitals for gastrointestinal bleeds was greater than the proportion of females either using ASA or neither NSAIDs nor ASA. This discrepancy may reflect the higher use of NSAIDs by females who, being three times more likely to develop rheumatoid arthritis than males (6), fill more NSAID prescriptions than men in all age groups $(6,7)$.

Both the increased use of NSAIDs by the elderly and their increased susceptibility to the damaging effects of NSAIDs place this group at an increased

TABLE 5

Proportion of NSAID users among gastrointestinal bleeders by age and sex

\begin{tabular}{lccc}
\hline Age (years) & Males: number $(\%)$ & Females: number $(\%)$ & Total: number $(\%)$ \\
\hline$<45$ & $5(11)$ & $1(13)$ & $6(12)$ \\
45 to 64 & $26(31)$ & $14(37)$ & $41(33)$ \\
65 to 74 & $17(25)$ & $13(42)$ & $30(30)$ \\
$\geq 75$ & $15(29)$ & $24(56)$ & $39(41)$ \\
\hline
\end{tabular}

risk for the development of NSAID-induced ulcer complications. The increasing incidence of arthritis with age is one of the reasons why the elderly consume one-half of all NSAIDs prescribed (8). The natural breakdown of the protective mucosal barrier lining the stomach and duodenum or the inability to appropriately metabolize NSAIDs and excrete them may increase exposure of the elderly to the damaging effects of NSAIDs. Furthermore, the use of corticosteroids and the concurrent illnesses commonly seen in elderly patients contribute to a threefold increase in the likelihood that NSAID-using elderly patients will develop ulcer complications $(2,3,6)$.

Armstrong and Blower (9), using a sample population of only patients with gastrointestinal bleeds who either died or underwent emergency surgery, found that patients taking NSAIDs with lifethreatening complications had an average age of 74 years and their non-NSAID using counterparts had an average age of 59 years. The present study, even with its wider parameters, also indi- cated that both male and female NSAID users were significantly older than their non-NSAID using counterparts. These studies suggest that NSAID use is more commonly seen in elderly patients who develop ulcers than in their younger counterparts. There was no significant difference between the average age of NSAID users and ASA users, perhaps because the elderly are just as likely to be using NSAIDs as they are to be using ASA.

Some authors (6) have proposed the use of prophylactic antiulcer therapy for NSAID users who have ulcer symptoms $(9,10)$. The analgesic properties of NSAIDs, however, may diminish the perception of pain (11). Hence, pain is not necessarily a predictor of the presence of a clinically significant lesion. Armstrong and Blower (9) demonstrated that $41.8 \%$ of NSAID users had a history of dyspepsia prior to their gastrointestinal bleed in comparison to $75 \%$ of patients not taking anti-inflammatory agents. In contrast, the NSAID users in this study were no more likely to present asymptomatically than 
either ASA users or non-NSAID users. NSAID users were less likely to require therapeutic endoscopy than either ASA users or non-NSAID users. The proportion of NSAID users who received surgical therapy, however, was not significantly different from that of the other two groups.

Armstrong and Blower (9) assert that NSAID users have a higher mortality than non-NSAID users. In contrast, this study indicates that both NSAID users and ASA users have a lower death rate than patients on neither drug. To determine if high death rates in the non-NSAID group were due to high rates of alcohol 'abuse', rates were recalculated in the absence of patients who were designated alcohol abusers. The death rate was still higher in the group on neither drug than in the NSAID and ASA groups. The reason for this difference remains unclear, but may be related to the different populations studied.

Both cigarette smoking and alcohol have been associated wth the development of ulcers (1). In fact, it has been

ACKNOWLEDGEMENTS: This work was supported in part by a Summer Student Research Grant provided by GD Searle and Co of Canada Ltd. Dr Fedorak is the recipient of a Clinical Investigatorship award from the Alberta Heritage Foundation for Medical Research.

\section{REFERENCES}

1. Roth SH, Fries JF, Abadi IA,

Hubscher O, Mintz G, Samara AM.

Prophylaxis of nonsteroidal anti-

inflammatory drug gastropathy:

A clinical opinion. J Rheumatol 1991;18:956-7.

2. Gabriel SE, Jaakkimainen L, Bombardier C. Risk for serious gastrointestinal complications related to use of nonsteroidal antiinflammatory drugs: A meta-analysis. Ann Intern Med 1991;115:787-96.

3. Jones MP, Schubert ML. What do you suggested that four-fifths of all gastric ulcer disease may be attributed to a combination of smoking and the use of NSAIDs (4). In this study, the proportion of NSAID users who abused alcohol was significantly less than that of the non-NSAID users. There appeared to be no significant difference between the proportions of alcohol-abusing NSAID and ASA users. These trends are not surprising, considering that most NSAID users are elderly females, a group of patients generally considered unlikely to be abusing alcohol (3). The proportion of patients smoking at least one pack per day did not vary significantly between the various groups. The proportion of NSAID users with a family history of ulcer disease was not significantly different from that of all other gastrointestinal bleeders, on average $20 \%$.

Neither NSAID prescription rates nor NSAID use rates for Alberta from 1988 to 1991 are available. However, a Saskatchewan-based cohort study of fatal upper gastrointestinal hemorrhage and/or perforation demonstrated that piroxicam, ibuprofen, naproxen, and

recommend for prophylaxis in an elderly woman with arthritis requiring NSAIDs for control? Am J Gastroenterol 1991;86:264-6.

4. Langman MJS. Epidemiologic evidence on the association between peptic ulceration and antiinflammatory drug use. Gastroenterology 1989;96:640-6.

5. Fenn GC, Robinson GC. Misoprostol: A logical therapeutic approach to gastroduodenal mucosal injury induced by non-steroidal anti-inflammatory drugs? J Clin Pharm Ther 1991;16:385-409.

6. Fries JF, Miller SR, Spitz PW, Williams CA, Hubert HB, Bloch DA. Toward an epidemiology of gastropathy associated with nonsteroidal anti-inflammatory drug use. Gastroenterology 1989;96:647-55.

7. Guess HA, West R, Strand LM, et al. Fatal upper gastrointestinal indomethacin had the highest NSAID user rates in Saskatchewan in 1983 (7). These rates paralleled the user rates found for piroxicam, naproxen, and indomethacin by this study.

The absence of denominator data for NSAID users precludes determination of which subgroup of NSAID users are at greatest risk of developing bleeding ulcers. Instead, the authors determined age groups of patients with a high proportion of NSAID users. Older patients, especially older females, had the highest percentage of NSAID use; this result is compatible with analytical studies of NSAID use and serious gastrointestinal complications, which report higher relative risks for elderly patients (2), and with Saskatchewan data (7), which show higher rates of NSAID use among the elderly, especially elderly women. Effective prophylactic therapy is likely to have its greatest impact on elderly patients. Studies to evaluate whether prophylactic therapy is costeffective in preventing NSAID gastrointestinal bleeds should target elderly users.

hemorrhage or perforation among users and nonusers of nonsteroidal anti-inflammatory drugs in Saskatchewan, Canada 1983. J Clin Epidemiol 1988;41:35-45.

8. Elliot DP. Preventing upper bleeding in patients receiving nonsteroidal anti-inflammatory drugs. DICP Ann Pharmacother 1990;24:954-8.

9. Armstrong P, Blower AL. Nonsteroidal anti-inflammatory drugs and life threatening complications of peptic ulceration. Gut 1987;28:527-32.

10. Edelson JT, Tosteson ANA, Sax P. Cost-effectiveness of misoprostol for prophylaxis against nonsteroidal anti-inflammatory drug-induced gastrointestinal tract bleeding. JAMA 1990;264:41-7.

11. Soll AH, Kurata J, McGulgan JE. Ulcers, nonsteroidal anti-inflammatory drugs, and related matters. Gastroenterology 1989;96:561-8. 


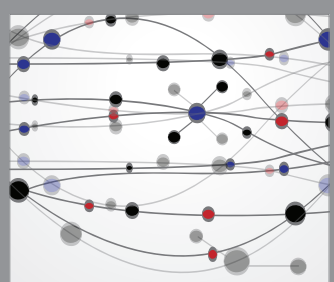

The Scientific World Journal
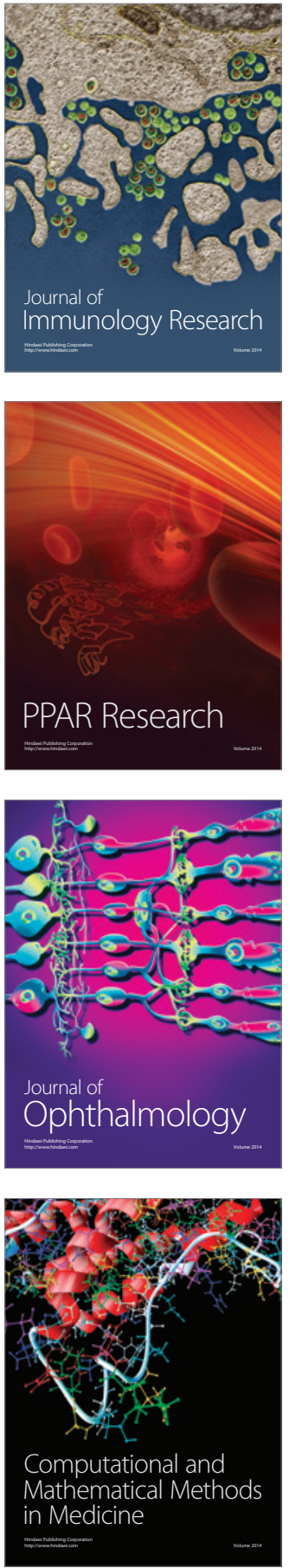

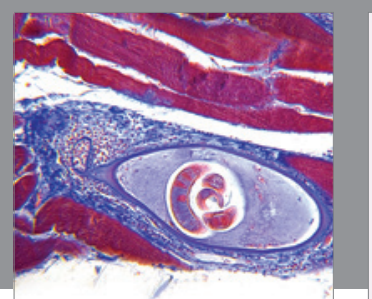

Gastroenterology Research and Practice

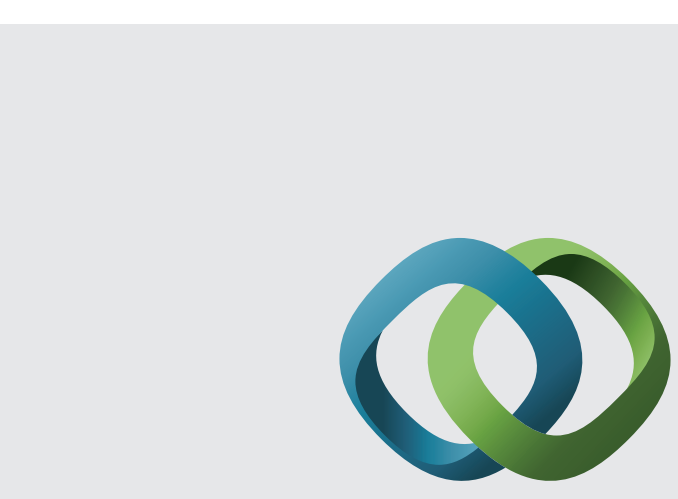

\section{Hindawi}

Submit your manuscripts at

http://www.hindawi.com
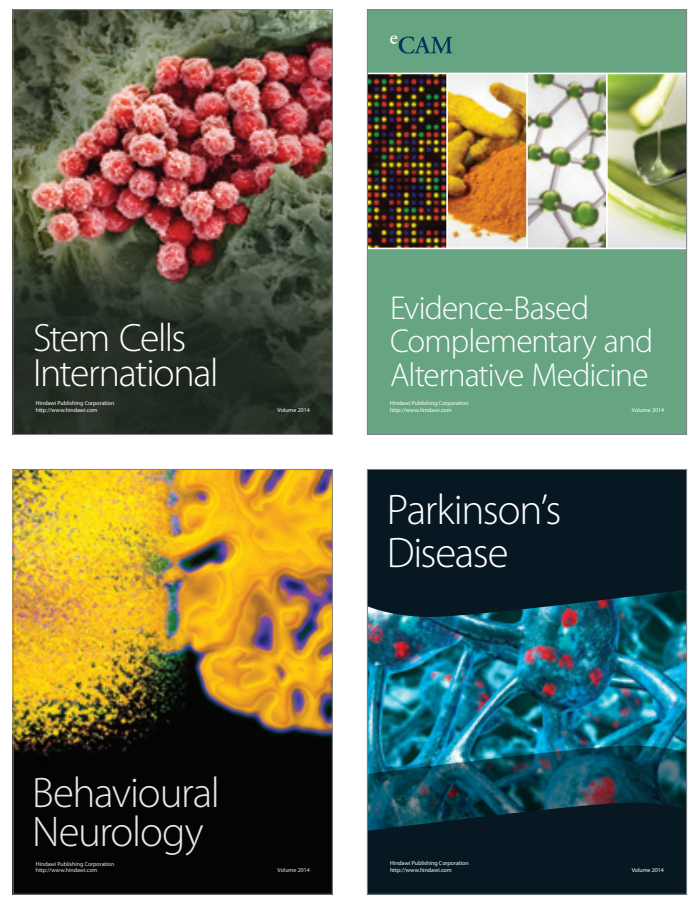
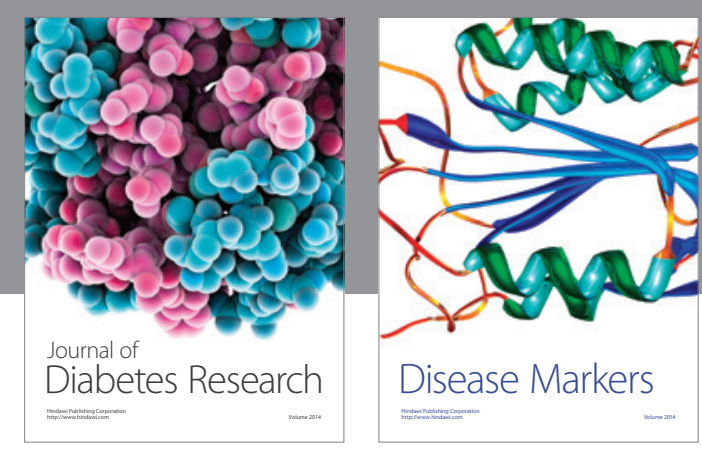

Disease Markers
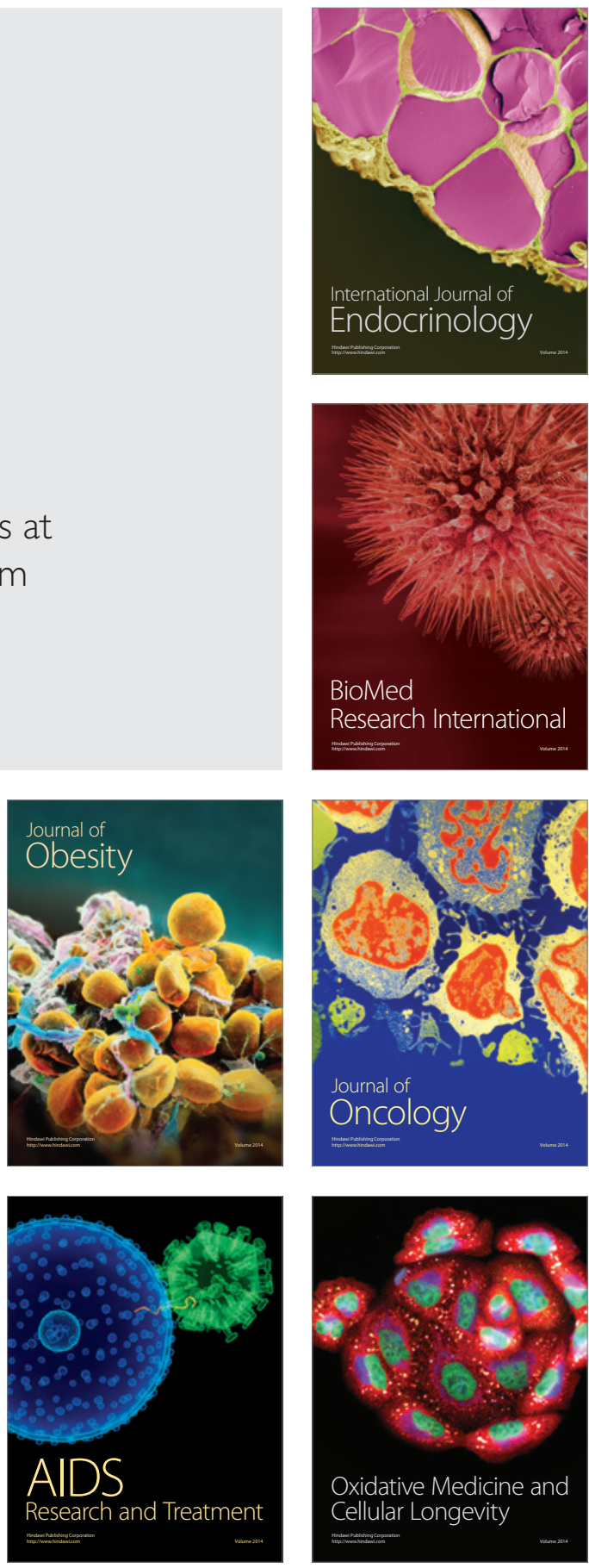